For those readers to whom a mathematical argument has no appeal, the general problem with which this note deals may be stated thus: If the concentration of a given substance, say urea, is higher in the blood than in the aqueous humour, the system, plasmaaqueous humour, is not in equilibrium and hence diffusion of urea should take place into the aqueous humour until the equilibrium condition ${ }^{4}$ of equal concentrations in the two fluids is achieved. Kinsey and Grant admit that this would happen in the absence of drainage and secretory activity. However, they claim that as soon as drainage occurs the concentrations become different, i.e., the system is no longer in equilibrium so far as urea is concerned, as defined thermodynamically. Now the second Law of Thermodynamics states that a system of this kind can only be maintained at a non-equilibrium position by the continued performance of work on it. Drainage of fluid away from the anterior chamber is not capable of performing the necessary work on the system, so that in the absence of secretory activity the concentration differences claimed by Kinsey and Grant are excluded by the second Law.

\title{
REFERENCES
}

Davson, H. and Quilliam, J. P. (1940).-Jl. Physiol., Vol. XCVIII, p. 141. INGRAHAM, R. C., Lombard, C. and Visscher, M. B. (1933).-Jl.gen. Physiol., Vol. XVI, p. 637.

Kinsey, V. E. and GRant, W. M. (1942).-Jl. gen. Physiol., Vol. XXVI, p. 131.

\section{THE DETECTION AND SIGNIFICANCE OF MELANO- PHORE EXPANDING SUBSTANCE IN URINE AND BLOOD WITH SPECIAL REFERENCE TO RETINITIS PIGMENTOSA*}

BY

\author{
JOSEPH R. MUTCH, M.D., D.O.M.S.(Lond.) and \\ Donald MaCKay, M.A. \\ WORKING FOR THE W. H. ROSS FOUNDATION (SCOTLAND) \\ FOR THE STUDY OF PREVENTION OF BLINDNE'SS
}

\section{Introduction.}

VERTEBRATES show two striking examples of pigment migration. One is migration of pigment within the skin melanophores of chromatically active cold-blooded vertebrates. The other is

Foot-note ${ }^{4}$ - The condition for equilibrium is that the chemical potentials are equal on both sides of the membrane; assuming that the activity coefficients are equal in the two fluids, for a non-electrolyte this is equivalent to stating that the concentrations must be equal.

\footnotetext{
* Received for publication, June 21, 1943.
} 
migration of the retinal pigment in amphibia and fish in response to varying light intensity.

It is now well established that the skin melanophore response is mediated by a melanophore dispersing hormone (B-hormone) secreted by the intermediate lobe of the pituitary. (Hogben, 1940; Hogben and Landgrebe, 1941). Mammals, including man, have no skin melanophores like those in amphibia and fishes. Yet their pituitaries are rich in B-hormone (Hogben, 1924) B-hormone or a substance with similiar action on the skin melanophores of the hypophysectomised frog has also been demonstrated in extracts from the hypothalamus and the eye, in blood, aqueous humor, cerebrospinal fluid, urine and colostrum.

\section{The Rôle of B-Hormone in Vision}

The only cells in mammals which might be comparable to the skin melanophores of amphibia and fish are the retinal pigment cells in the eye. B-hormone might therefore mediate changes in the pigmented layer of the retina. Thus when Jores and Caesar (1935) treated a'frog's eye with a solution of B-hormone the retinal pigment migrated to the dark position more rapidly. After instilling extracts containing B-hormone into the human eye, Jores (1933) Jores and Hotop (1934) and Bastile (1939) found that dark adaptation occurred more rapidly in the treated than in the untreated eye, and also more rapidly than in a normal eye.

Several workers report that the blood level of melanophore dispersing substance (presumed to be B-hormone) varies according to whether the animal is kept on a light or a dark background. Jores (1933) found an increased amount of the activity in the blood and aqueous humor of rabbits which had been kept 1-2 days in darkness. Zondek (1935) quotes an observation (no reference given) that when cats were kept a long time in darkness the quantity of melanophore dispersing substance in their blood and aqueous humor increased. Nevinson (1940) found a diurnal variation in the amount of activity in the blood of the rat. Jores (1933) estimating the amount of hormone present in the pituitary gland of different species-man, guineapig, cat, fowl-found relatively more in the pituitaries of those animals with good nightvision, e.g., the cat.

Largely because of unsatisfactory assay methods, these experiments are not well substantiated. An account of a reliable and accurate method will shortly be published (Landgrebe and Waring, 1943b). Jores and Caesar squeezed the frog's pituitary with forceps and observed that the retinal pigment migrated to the dark position. Yet hypophysectomy does not alter the movement of retinal pigment in response to light and darkness in 
either frogs (Matuo, 1935) or toads (Okamoto, 1937). Conse-. quently it may be doubted whether B-hormone is a primary factor in retinal pigment migration. We should also remember that retinal pigment migration has not been definitely demonstrated in mammals as a normal physiological process. If it takes place it does so only slightly.

Recent work done on dark adaptation as a test for vitamin A deficiency (Thomson et al.1939) shows that the results vary greatly owing to faulty technique, and to the ignoring of physiological and psychological influences. Pituitary extracts dilate the pupil in the enucleated eye of the frog (Jores and Caesar, 1935) and when instilled into rabbits' eyes cause pupillary dilatation in 94 per cent. of cases (Geiling,. 1926). Hence the variation in the rate of dark adaptation might have been due to the difference in size of the two pupils. As the extract of B-hormone was dropped on to the surface of the eye, the only way that it could reach the retinal pigment is through the general circulation and for reasons which will be clear later it is unlikely that the concentration present could have influenced the rate of dark adaptation. Buschke (1934) repeated this experiment but hé was unable to confirm Jores' and Caesar's claim that the B-hormone treated eye showed more rapid dark adaptation than that of a control. Even if $\mathbf{B}$-hormone is a factor in normal dark adaptation, retinal pigment migration need not be involved. The hormone may act, as Jores (1933) suggests, by accelerating the rate of formation of visual purple. Adequate confirmation for the claim that there is an increased level of B-hormone in the blood of rabbits kept in darkness has not yet been presented (If the observation is correct it is the opposite of what is found in amphibia (Landgrebe and Waring,-1941).

These experiments show that as yet we do not know whether B-hormone plays any physiological rôle in vision. There is thus little or no data to indicate the rôle of the hormone in pathological conditions such as retinitis pigmentosa.

\section{Retinitis Pigmentosa and its Relationship to B-Hormone}

As Cunningham Dax (1940) points out, it was the reçognition of retinitis pigmentosa as a feature of the Laurence-Moon-Biedl syndrome which first prompted the idea that the disease in its more usual presentation might be associated with diencephalic and endocrine disturbances. Zondek (1935) stated rather dogmatically "Retinitis pigmentosa, both in the typical and atypical form, plus disturbances in the pituitary diencephalic region, is typical for the Laurence-Biedl syndrome. Sometimes retinitis pigmentosa may be the sole clinical evidence of diencephalic disturbance:" 
Cunningham-Dax's demonstration (1938) that urine samples from 20 retinitis pigmentosa patients when injected into frogs expanded the skin melanophores, led to renewed interest in the interptetation of retinitis pigmentosa as an endocrine or diencephalic disturbance.

The aetiology of retinitis pigmentosa is obscure and controversial. The essential feature in the pathology is a progressive degeneration of the retinal neuroepithelium, primarily of the rods', which is followed by a general atrophy of the whole tissue. There is associated glial overgrowth, depigmentation of the retinal epithelium with migration of pigment into the retina, and an obliterative sclerosis of the retinal vessels (Duke-Elder; 1940).

In the absence of physiological knowledge, the nature of the primary change has been the subject of considerable speculation. Duke-Elder has reviewed the various theories in some detail. The older view regarded the pathological picture as the sequel to a degenerative sclerosis of the choroidal blood vessels. The sclerosis leaves the neuroepithelium insufficiently nourished so that it atrophies.' Masses of pigment then migrate into the atrophied areas from the pigmented epithelium and accumulate around the vessels. This migration was cońsidered rather as a mechanical sequel to choroidal atrophy than as a primary manifestation. Wagenmann (1890) sectioned the posterior ciliary arteries in a rabbit. He presumed that the destruction of the retinal neuroepithelium which followed was due to cutting off the source of nourishment. As he also cut the nerves running with the arteries this interpretation is open to question. Nicholls (1938) repeating his work found little resemblance in the changes produced to the picture of pigmentary degeneration usually seen in retinitis pigmentosa.

The theory at present commanding widest support regards the degeneration of the neuroepithelium as primary, and the vascular sclerosis as secondary. The disease is classed as an "abiotrophy" -i.e., "The premature senility and death of a specified tissue." There was little positive evidence in favour of the theory until Bourne, Campbell and Tansley (1938) described a breed of rats in which the typical picture of pigmentary degeneration was handed down as a Mendelian recessive. They showed histologically that the process of degeneration in these rats started in the cell nuclei.

Other workers, stressing the Laurence-Moon-Biedl syndrome, regard retinitis pigmentosa as the expression of an endocrine disturbance. The abnormal hormonal influences are believed to arise from a congenital lesion in the pituitary-hypothalmic system (Zondek, 1935). They consider the presence of a melanophoreexpanding substance in the urine of retinitis pigmentosa patients 
particularly significant. We know so little, however, of the action of individual hormones on the retina that the theory remains no more than an hypothesis. Mecca and others of the Italian school for example (see Cunningham Dax, 1938) believe the cause of retinitis pigmentosa to be spasm of the retinal vessels due to a hormone or hormones acting locally on a retinal circulation rendered abnormally sensitive by a hereditary developmental factor. We at least know that B-hormone freed from the posterior pituitary vasopressor fraction has no vasoconstrictor action.

Cunningham Dax (1940) recently formulated a wider hypothesis incorporating both the " abiotrophic" and " endocrine" theories. Like the proponents of the abiotrophic theory, he looks upon retinitis pigmentosa as a degeneration of the nervous elements of the retina. This degeneration is but one manifestation of a heredo-maldevelopment of the diencephalon under the influence of a pathological gene. He recalls that the optic vesicles and diencephalon have a common developmental origin. The heredomaldevelopment may result on the one hand in obvious diencephalic disturbances of varying degree (e.g., the Laurence-MoonBiedl syndrome) while on the other hand (e.g., ordinary uncomplicated cases of retinitis pigmentosa) there may be at first sight few or no diencephalic disturbances. Such apparently uncomplicated cases, may, however have diencephalic or endocrine abnormalities not immediately obvious on routine examination, e.g., abnormalities in water-salt metabolism, sugar tolerance curves, body temperature, vitamin metabolism, fat distribution, sexual development, urinary excretion, etc. To discover whether any such abnormalities existed in apparently uncomplicated retinitis pigmentosa, Dax planned an investigation covering 11 cases. He found a number of abnormalities common to several of the patients. The presence of a melanophore-expanding substance in the urine and in the circulation was among one of his more constant findings. Of 11 patients, 8 had a melanophore-expanding substance in their urine, but only 4 had a similar substance in their blood.

This hypothesis may adequately explain a certain percentage of retinitis pigmentosa cases, but Sorsby (1938) points out that the significance of retinitis pigmentosa in the elucidation of the pathology of the Laurence-Moon-Biedl syndrome has been overrated, for the fundus lesion is not generally a typical degeneration of the retina. Atypical retinitis pigmentosa being the rule in the Laurence-Moon-Biedl syndrome. Moreover in over $2 / 3$ of the retinitis pigmentosa cases collected by Bell (1922) no associated abnormalities were noted by her either in the affected person or his relatives. 
The presence of excess B-hormone in the urine and blood of retinitis pigmentosa patients, if conclusively proved, may thus be due to an endocrine disturbance co-existing with the retinitis pigmentosa as the result of degenerative changes in the embryological precursor of the diencephalon and optic vesicles. The hormone need not necessarily play any part at all in the causation of the disease.

\section{The Assay of B-Hormone}

The various assays of B-hormone are based on the fact that it expands the skin melanophores of cold-blooded vertebrates.

The method of assay must be (1) Specific to B-hormone, (2) reliable, (3) capable of yielding quantitative results. Lack of a standardised technique has led to contradictory results. In a recent review of assay methods, Landgrebe and Waring (1941) point out the advantage of the Hogben and Gordon (1930) technique. Most workers have employed one or other of three methods of assay, viz.: (1) the material to be tested is injected into the dorsal lymph sac of a normal on hypophysectomised frog or toad, (2) the amphibian skin is suspended in the unknown solution or (3) the unknown solution is perfused through an isolated amphibian limb (McLean, 1928). The last two methods are limited for practical purposes by the necessity of using a fresh test object for each assay.

Some workers accept macroscopic darkening of the skin of the test animal when compared with a control's as proof that B-hormone is present in the solution. Others seeking more accurate results compare the appearance of the individual melanophores in the web before and after injection. With certain reservations (see Landgrebe and Waring, 1943b) the length of time the animal remains dark or the melanophores remain expanded gives a further criterion of potency.

Macroscopic matching of colour change is difficult. The concentration of melanophores per unit of skin may vary considerably in different animals. A "Xenopus" toad with densely packed melanophores can show macroscopic darkening when the individual melanophores as seen under the microscope show only a very slight response. (Landgrebe and Waring, 1943b). This is important when we remember that in normal animals a number of substances other than B-hormone can indirectly expand melanophores by their action on the pituitary.

Toads also vary in sensitivity to B-hormone depending on the length of time they are kept on a white background. One c.c. of the same test substance may thus produce negative results in one toad and positive results in another animal which is more sensitive. 
Results from different laboratories using different animals may, therefore, not be comparable.

Boiling with $\mathrm{N} / 10$ caustic soda increases the melanophoreexpanding properties of B-hormone about twofold and also protongs the response. Many workers, including Dax (1938) have therefore treated extracts with caustic soda before assaying them. When the length of time an animal remains dark after an injection of B-hormone is used as the basis for assay, such caustic soda treatment may give fallacious results, for prolongation of the response is not necessarily proportional the amount of B-hormone originally present. The alkali may potentiate by acting on a pituitary constituent other than melanophore hormone (Landgrebe and Waring, 1941 and 1943a).

The most reliable assay method for B-hormone based on the melanophore response is that adopted by Hogben and Gordon (1930) and modified by Landgrebe and Waring (1943b). They employ the South African clawed toad Xenopus laevis and with twelve test animals can discriminate between doses differing by not less than 20 per cent. Five arbitrary values (1-5) are assigned to chosen grades of melanophore expansion. Completely contracted melanophores are represented by " 1 " and completely expanded melanophores are represented by " 5. " The response is measured by "reading" the melanophores in the posterior web of the toad before and at intervals after, injection. The value holding at the time of observation is the melanophore index. By plotting response against time we can get two criteria for relative potency. It is important to ascertain the sensitivity of the toads by injecting a standard dose of purified B-hormone. Hypophysectomised animals should be employed when possible and certainly in all cases to confirm positive results. Few substances expand the melanophores of an hypophysectomised frog or toad. (Landgrebe and Waring, 194I). When hypophysectomised animals are not available and ordinary toads are employed, conditions must be standardised and one should remember the possibility of endogenous pituitary stimulation by injected substances (e.g., the A-P-L- fraction of pregnancy urine). A rise of less than 1.5 units in the melanophore index is of doubtful significance in normals. It must be pointed out that a rise of 1.5 units' $(e . g ., 1$ to 2.5$)$ may cause appreciable macroscopic darkening in a toad with closely set melanphores.

\section{Melanophore-Expanding Substance in Urine}

Using one or other of the assay techniques mentioned, melanophore-expanding substance has been detected in the urine of patients suffering from conditions other than retinitis pigmentosa. 
Collen and Drouet (1933) assayed urines in different illnesses. They obtained positive results only in cases of hyperthyroidism, migraine, pituitary tumours and retinal bleeding. 'They also detected a melanophore-expanding substance in the urine during pregnancy and in the early stages of menstruation.

Cunningham Dax (1938) using frogs, injected 0.3 to 1.0 c.c. of urine previously alkalanised with $1 / 10 \mathrm{~N}$. $\mathrm{NaOH}$ and heated in a boiling water bath for half an hour. Darkening of the frogs was considered to represent a positive result. The urines of 20 patients suffering from retinitis pigmentosa were all positive. $\mathrm{He}$ also obtained positive results from urine of normal women passed on the day preceding the menstrual flow or on the first day of the period and from urine in a case of hyperthyroidism with cutaneous pigmentation. The urine of controls did not yield positive results unless 3c.c. were used, or unless the samples were made alkaline with $5 \mathrm{~N}$ instead of $1 / 10 \mathrm{~N}$ caustic soda. In his later series of 11 patients, Cunningham Dax obtained positive results from 9 of the 11 specimens.

Raza and Spurrell (1937) tested normal urines for melanophoreexpanding substance. Using intact pale frogs and judging melanophore expansion by the Hogben and Gordon technique, they assayed 52 non-pregnant healthy adults (34 males and 18 females) and 46 pregnant women. A rise in the melanophore index of less than 2 was counted a "weak" positive and a rise of more than 2 a "strong" positive. From 2 to 5c.c. of urine at $\mathrm{pH} 7 \cdot 2$ was injected into the dorsal lymph sac. There were 38 per cent. of positive reactions among the non-pregnant adults ( 41 per cent. in the males and 33 per cent. in the females). Ninety-eight per cent of the pregnant females gave positive reactions (30 " strong " and 15 " weak"). There was no correlation with age, sex or colour. The urine was not alkalinised. Raza and Spurrell noted, however, that alkalinisation enhanced the reaction. The reaction was completely abolished by shaking the urine up with charcoal or with a fine precipitate of benzoic acid or by dialysing it through collodion or cellophane. They were unable to recover the active principle from the absorbate.

Landgrebe and Waring (1941), using the Hogben and Gordon assay technique, tested the urines of various healthy adult subjects. Most of their urines produced a slight melanophore response in intact toads. Only a few affected hypophysectomised animals. One of these, a very potent sample, did not have its activity abolished by treatment with charcoal. B-hormone prepared from pituitary powder is absorbed on charcoal and can be recovered by elution with phenol. For this reason they suggest that the melanophore excitant present in the urines may on occasion be a substance other than B-hormone. In this particular case no 
reason (e.g., ingestion of drugs, intercurrent disease) could be found to explain the positive result. Jores (1936) found that treatment with charcoal did not invariably abolish the urinary reaction which he therefore did not consider specific for B-hormone. Landgrebe and Waring also injected subcutaneously large doses of purified B-hormone extracts into mice and toads. They were unable subsequently to detect any traces of the hormone in the urine. More recent work has shown that B-hormone is excreted in the urine only after it has reached a very high level in the circulation such as after intravenous injection (Landgrebe and Waring, 1943a). Jores, in the paper just quoted, found that while melanophore hormone injected into the circulation could be identified in the blood the subsequent urine gave a negative reaction. He was unable to find B-hormone in the blood of subjects with a positive urine.

These results show that no definite conclusions can at present be drawn from urine assays. Until the specificity of the reaction is unquestioned, the presence of a substance exhibiting melanophoreexpanding activity in the urine cannot be taken to indicate overaction or pathological disturbances of the pituitary.

\section{Melanophore-Expanding Substance in Blood}

Several workers have shown that melanophore-expanding substance can be detected in the blood (Landgrebe and Waring, 1941).

Cunningham-Dax, in his series of 20 retinitis pigmentosa patients, (1938b) assayed blood samples as well as urines. He obtained positive results in all 20 cases. In his other series of 11 . cases he obtained positive results in 7 of the 9 samples assayed.

Using the Hogben and Gordon assay we tested blood samples from 9 cases of uncomplicated retinitis pigmentosa and from 7 normal controls, to find whether, if a melanophore-dispersing substance were present, there was any significant difference in the amount present in retinitis pigmentosa samples as compared with controls.

Normal toads were chosen for the preliminary investigations. The intention was to repeat the series on hypophysectomised animals if significantly positive results were achieved. The animals were kept in water in tins with a white background under constant illumination so that the melanophores could normally be contracted. The water was renewed once a week on the day after feeding.

The solution to be tested was injected into the dorsal lymph sac. The needle was inserted through the thigh muscle of the right leg to prevent back leakage. The melanophores in the posterior web were read every half-hour until the maximum response bad 
been attained or until it was clear that there was no expansion. An equal amount of extract was injected into each of a pair of toads unless otherwise stated. The average melanophore expansion was recorded. Each pair was rested for a week between one injection and the next.

The sensitivity of the toads to melanophore hormone was ascertained beforehand by injecting them with solutions of B-hormone of varying strength, prepared by the method of Landgrebe and Waring (1941). Toads of approximately equal sensitivity wère chosen for the experiment. Each required about 4 to 6 Landgrebe and Waring ( $\mathrm{L}$ and $\mathrm{W}$ ) units of $\mathrm{B}$-hormone to produce a maximum response i.e., to raise the melanophore index to 5 .

It was decided to extract the melanophore-dispersing substance with reagents rather than to inject whole blood or serum into the test toads, for the following reasons : (1) not more than 1c.c. of serum or blood can be injected into one toad, and when toads were injected with up to 1c.c. of whole blood no significant response was obtained; (2) serum or whole blood has a toxic effect on toads which can therefore be used once only.

From experience gained in making extracts from pituitary posterior lobe, the following methods of extraction were devised. (1) The blood sample was added to ten times its own volume of acetone. The precipitated proteins were filtered off, washed in acetone and dried in a blast of warm air. The dried product was then powdered. B-hormone activity is precipitated along with, the proteins. To check this, some B-hormone was added to rabbits' blood which was then mixed with acetone. No melanophore-expanding activity was detected in the supernatant acetone although it was present in the precipitate. The powder thus obtained can be stored and extracted when convenient, for the hormone maintains its potency indefinitely in the dry state. Acetone-treatment was employed when a sample could not be assayed immediately. (2) The blood sample or the prepared powder was mixed with five times its own volume of absolute alcohol and boiled in a water bath for 3 minutes. The mixture was then centrifuged. After evaporating the supernatant alcohol in a water-bath, the residue was dissolved in 2c.c. of warm distilled water. The solution was centrifuged and the supernatant fluid injected into the toads.

Caustic soda treatment of the extract was not employed for the reasons described previously (page 440).

The efficiency of the extracting procedure just described was tested in a series of experiments using rabbit blood.

- Several samples of rabbit blood were first assayed to discover whether melanophore hormone is normally present in the rabbit's 
circulation. Four c.c. of blood from the right ear vein of a young male rabbit were collected in acetone. The precipitate was washed in acetone, dried, powdered and extracted with alcohol as described above. The final aqueous solution was injected into three test animals. The melanophore index was raised by one unit. Repetitions of the experiment at different times and on different animals showed either no change or negligible expansion of melanophores.

Confirmation was sought of Jores' observation that there is an increased amount of hormone in the blood of rabbits kept for one or two days in darkness. Two of the rabbits mentioned above were kept in complete darkness for three weeks. They were fed regularly and kept at a constant temperature. At the end of each week a blood sample was withdrawn from the ear vein of each rabbit, extracted and assayed. Only at the end of the first week, in the case of one rabbit, was a positive result obtained. This could not be repeated on subsequent occasions.

Negative results were also obtained when heparinised and citrated whole blood were directly injected into the test toads.

An estimation was made of the percentage of added B-hormone recoverable from rabbits' blood. It was assumed from the above experiments that B-hormone is not normally present in rabbits' blood. Twelve L. and W. units of the same extract of B-hormone were added to 2c.c. of rabbits' blood and to 2c.c. of distilled water. It was known that from 4-6 L. and $\mathrm{W}$. units of B-hormone would give a maximum response in the test toads used. One c.c. of the distilled water solution was injected into each of 2 tést toads. The blood was extracted with alcohol and the final aqueous solution injected equally into 2 other test toads of equal sensitivity. Six units were present in the hormone-in-water solution. A nearly maximal response was attained, the index being raised by 3.5 units. In the case of the hormone-in-water solution the index was raised by 2 units. This is little more than half the response evoked by the aqueou's solution. Thus it would appear to contain from between 3 to 4 units of B-hormone. The experiment shows that the direct alcohol extraction method can recover from 50 to 60 per cent. of the added purified B-hormone. It suggests, but does not prove, that the method will satisfactorily extract " native "' B-hormone if present in blood.

Blood samples were taken from :-(1) 7 healthy medical students, and (2) 9 well-established cases of retinitis pigmentosa. Five to 10c.c. were drawn from an arm vein in each subject and immediately precipitated in acetone. A powder was prepared and extracted with absolute alcohol in the way already described. The final extract from each samplè was divided between two test toads.

Tables I and II record the melanophore response : to each sample: Relevant ophthalmological data is given for 
MELANOPHORE EXPANDING SUBSTANCE

TABLE 1.-Control Series

\begin{tabular}{|c|c|c|}
\hline Subject & $\begin{array}{r}\text { Melanophore } \\
\text { Index } \\
\text { raised by }\end{array}$ & Pigmentation \\
\hline $\begin{array}{l}\text { Male } 1 \\
\text { Male } 2 \\
\text { Male } 3 \\
\text { Male } 4 \\
\text { Male } 5 \\
\text { Male } 6 \\
\text { Male } 7\end{array}$ & $\begin{array}{l}2.0 \\
0.5 \\
0.5 \\
0 \\
1.5 \\
0.5 \\
0.5\end{array}$ & $\begin{array}{l}\text { Dark } \\
\text { Fait } \\
\text { Medium } \\
\text { Dark } \\
\text { Fair } \\
\text { Medium } \\
\text { Dark }\end{array}$ \\
\hline
\end{tabular}

Table 11.-Retinitis Pigmentosa Series

\begin{tabular}{|c|c|c|c|c|c|}
\hline Subject & $\begin{array}{c}\text { Melanophore } \\
\text { Index } \\
\text { raised by }\end{array}$ & Age & $\begin{array}{l}\text { Certified } \\
\text { Blind }\end{array}$ & $\begin{array}{c}\text { State of } \\
\text { Vision }\end{array}$ & $\begin{array}{c}\text { Associated } \\
\text { Defects }\end{array}$ \\
\hline Male 1 & 0.5 & 37 & 1932 & Hand Movements & External Squint \\
\hline Male 2 & 0.5 & 42 & 1935 & Finger Counting & Deaf \\
\hline Male 3 & 0.5 & 32 & 1937 & $3 / 60$ & Posterior Cortical \\
\hline Male & 1.0 & 48 & 1934 & $6 / 24$ & Deaf. \\
\hline Male & $1 \cdot 5$ & 27 & 1932 & P.L. only & none \\
\hline Male 6 & 0.5 & 20 & 1934 & $6 / 24$ & none \\
\hline Female $?$ & 2,0 & 29 & 1932 & Finger Counting & Fits \\
\hline Female 8 & $1 \cdot 0$ & 24 & 1932 & Hand Movements & External Squint \\
\hline Female 9 & $2 \cdot 0$ & 41. & 1936 & $6 / 36$ & Deaf \\
\hline
\end{tabular}

TABLE III-Comparison between Controls and Retinitis Pigmentosa Patients

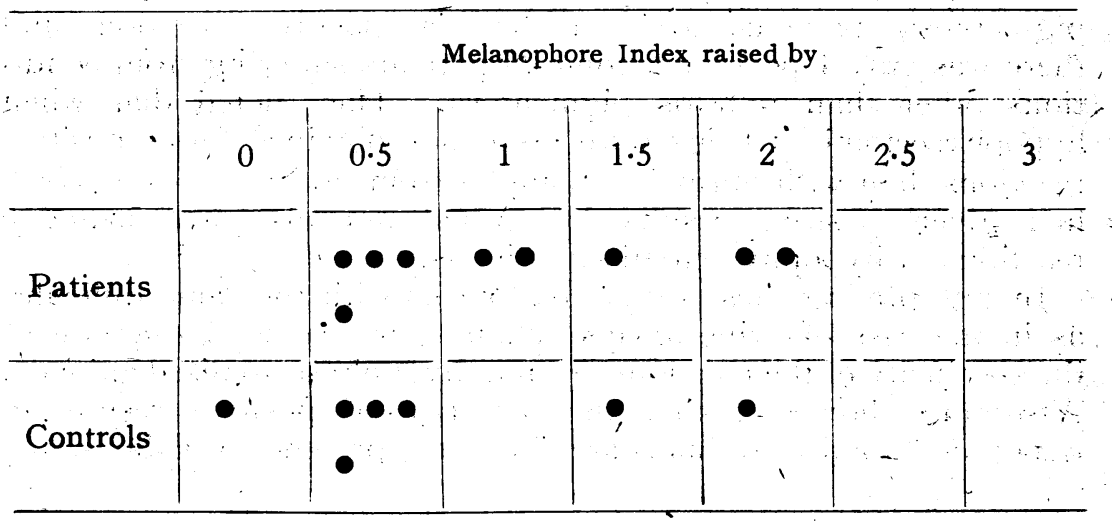


each retinitis pigmentosa patient. In the case of the normal subjects the state of general pigmentation is recorded. Table III compares the different grades of response evoked by the samples from the two groups of subjects.

The results varied from a barely perceptible response to a rise of 2 in the melanophore index. As the toads were not hypophy'sectomised it is difficult to exclude the possibility that protein or other material in the extract had stimulated the animals' own pituitary to produce melanophore hormone. Results showing a rise of 1.0 or less may therefore be considered negative. Out of the 9 retinitis pigmentosa patients only in 3 cases was the blood sample definitely positive. Of the 7 controls 2 samples were definitely positive. These controls had neither the features nor a family history of retinitis pigmentosa, nor did they suffer from any other disease. Both the retinitis pigmentosa positives were females. Neither was menstruating at the time and they were regular in their periods. In the retinitis pigmentosa cases there is no relationship between the melanophore response and the age of the patient or the extent of pigmentation in the eyes. There is no relationship between the degree of pigmentation of the hair, skin, etc., in the control subjects and the melanophore response to their blood extracts.

These experiments do not confirm the claim that the blood of retinitis pigmentosa patients regularly contains a melanophore expanding substance in excess. McDonald and Adler (1942), after carrying out a series of assays for active melanophore expanding substance in human blood, came to the same conclusion. They injected 1c.c. of whole serum into the dorsal lymph sac of a light adapted frog and watched for maximal or submaximal darkening of the skin which, when confirmed by microscopical evidence of web melanophore expansion, they considered a positive reaction. In their first series of tests normal frogs were used. Of 43 retinitis pigmentosa patients, 12 had positive reactions. In their second series they used hypophysectomised frogs. Of 12 retinitis pigmentosa patients, only 1 had a positive reaction and there was only 1 positive among 20 patients suffering from conditions other than retinitis pigmentosa. They noted that when hypophysectomised frogs were used they obtained fewer positive reactions than with normals. Samples from several patients which had given positive results in normal animals gave negative reactions in hypophysectomised animals.

In interpreting these results one meets with the same difficulty as in the case of urine assays-namely, we cannot be certain of the specificity of the reactions, even in hypophysectomised animals. Assuming, however, that the majority of positive results in hypophysectomised animals are due to the presence of B-hormone, 
iit may be suggested, to explain the scantiness of positive reactions, that unlike prepared B-hormone added " in vitro," B-hormone secreted by the pituitary is adsorbed on other proteins and therefore not extracted by alcohol. The elucidation of this possibility awaits refinements in extraction procedure. Alternatively B-hormone may be destroyed almost as quickly as it is secreted, and thus be present only intermittently in the circulation. We know that the circulating blood of an eel kept in darkness contains ten times as much B-hormone as is contained in the animal's pituitary (Waring and Landgrebe, 1941). A rabbit's pituitary contains from 1,000 to $2,000 \mathrm{~L}$. and $\mathrm{W}$. units of $\mathrm{B}$-hormone when dried and extracted. The experiments on the assay of B-hormone in rabbits' blood quoted earlier show that if $B$ is present it cannot be in a concentration greater than 2 units per c.c. Assuming that the blood volume of the rabbit is about 150 c.c. the greatest amount of B-hormone circulating at any one time would not be more than 300 units. An experiment was therefore carried out to obtain some idea of the rate of destruction of B-hormone in the mammalian circulation. Known doses of melanophore hormone were injected into rabbits' blood and samples taken from an ear vein at intervals afterwards.

(1) A 3c.c. blood sample drawn from the ear vein of a rabbit and assayed. No rise in the melanophore index was recorded. One and a half c.c. of potent melanophore prepared by the method of Landgrebe and Waring (1941) and containing 45,000 L. and W. units, was injected into the ear vein of the same rabbit. Any possible " pressor "' contamination was first destroyed by boiling the extract with two drops of $\mathrm{N}$. caustic soda (caustic soda does not potentiate B-hormone prepared by this method). The solution was neutralised before injection. At 15 minutes, 80 minutes and 120 minutes after injection $1 \frac{1}{2}$ c.c. of blood were withdrawn from an ear vein in the other ear. Each of these samples was extracted by the alcohol method and assayed on two test toads. Both the 15 minute and 80 minute samples evoked a maximal melanophore response, raising the index to 5 in each case. The 120 minute sample was negative.

(2) Another rabbit was injected intravenously with 3,000 units of pressor-freed B-hormone, One-and-a-half c.c. of its blood assayed previously to injection showed no melanophore response. Further samples of blood were taken and assayed 45 minutes, 110 minutes, and 210 minutes after injection. The 45 minute samples produced a definite rise of 2.5 units. The other samples were negative.

The concentration of hormone in the rabbit's blood just after injection in the first experiment would be about 300 units per c.c. This concentration was therefore reduced in two hours to less than 
4 units per c.c.-the minimum necessary to give a positive melanophore response in two toads. In the second experiment a concentration of 20 units per c.c. was set up initially. The result from the assay of the blood sample taken 45 minutes afterwards shows that there must have been about 4 units per c.c. in the circulation at that time.

These experiments show that B-hormone disappears rapidly from the rabbit's circulation. The same may hold good in man, for when Jores (1936) injected the hormone intravendusly into normal subjects he found that it rapidly disappeared from the circulation. If this is true, and if secretion from the pituitary is intermittent, "positive" results might be obtained in a subject at one time and " negative" "results at another.

\section{Summary}

The literature on the possible rôle of B-hormone in vision and its relationship to the pathogenesis of retinitis pigmentosa is briefly reviewed, and the techniques. for the assay of B-hormone are discussed.

The results of several urinanalyses for B-hormone are summarised. Reasons are quoted for considering the present assays for B-hormone as not completely specific

Experiments are reported in which blood samples from 9 retinitis pigmentosa patients were assayed and compared with blood samples from 7 normal controls. Details are given of the process of extraction and assay employed. Only 3 of the 9 retinitis pigmentosa samples were definitely " positive." Two of the 7 control samples gave a positive result.

It is concluded that the blood of retinitis pigmentosa patients does not regularly contain a melanophore-expanding substance and that such a substance may occasionally be present in "normal " bloods.

- A further experiment is described showing that in the rabbit B-hormone injected intravenously disappears very rapidly from the circulation.

This investigation commenced under the supervision of Professor Lancelot Hogben, Biology Department, University, Aberdeen. We wish to acknowledge our gratitude for the valuable help and advice given.

We also acknowledge the very considerable assistance given by Dr. Landgrebe and Dr. Waring.

\section{BIBLIOGRAPHY}

Bastile (1939).-Ann. di Ottal. e Clin. Ocul., Vol. LXVII, p. 412; Sum. Arch. Ophthat., Vol. XXIII, p. 867, 1940.

BELL. J. (1922),-Treasury of Human Inheritance. London, Vol. II, i, 1922-23. 
Bourne, M, C., CAMPBELL, D. R, and TANSLEY, K. (1938)-Trans. Ophthal. Soc. U.K., Vol. CVIII, i, p. 234.

Buschке; W. (1934).-Klin. Wschr., Vol. XIII, p. 178.5.

Collex, R. and Drouet, P. L. (1933).-Bull. Acad. Med., Paris, Vol. CIX, .p. 794 .

CunNingHaM Dax, E. (1938a).-Brit. Jl. of Ophth., Vol. XXII, p. 345.

(1938b).-Trans. Ophthal. Soc.U.K., Vol. LVIII, p. 227.

(1940).-Quart.Jl.Med., Vol. XXXIII, p. 263.

DUKE-ELDER, W. S. (1940).-Textbook of Ophthaimology, Vol. III.

GEILING; E. M. K. (1926).-Physiol. Rev., Vol. VI.

HOGBEN, L. (1924). -Pigmentary Effector System.

HogBen, L. and Gordon, C, (1930). Jl. Exp. Biol,, Vol. ViI, p. 286.

Hogben, L. and Landgrebe, F. W. (1940):-Proc. Roy. Soc.Med., Vol. CXXVIII, p. 317.

JORES, A. (1933) -Klin. Wschr, Vol. XII; p.. 1599.

JORES, A. and CAESAR (1935).-Pfluger's.Arch., Vol. CCXXXV, p. 724.

Jores, A. and Hotop, H. (1934), -Z. Vergl. Physiol., Vol. XX, p. 699.

JoRES, A. (1936):-Klin. Wschr., Vol. XV, p. 1433.

LANDGREBE, F. W. and WARING, H. (1941).-Quart. Jl. Exp. Physiol., Vol. XXXI, p. 31 .

- (1943a).-Quart. Jl. Exp. Physiol.

(1943b). - In press.

- Matuo, K. (1935).-Okayama Igak. Zasshie, Vol. XLVII, p. 2387.

MCDonald, P. R. and AdLER, F. H. (1942).-Arch. Ophthal., Vol. XXVII, p. 264.

Mclen A. J. (1928).-Jl. Pharm., Voi. XXXIIT, p. 301.

Nevinson, L. (1940)-Proc. National Acad. Sci. U.S.A., Vol. XXVI, (4), p. 257.

N.ICholls (1938).-Brit. Jl. Ophthal., Vol. XXII, p. 672.

Okanuto, T. (1937).-Zentralb. Ges. Exp., Vol. CI, p. 155.

RazA, S. H. and'SpurReli, W. R. (1937):-Jl. Physiol., Vol. XC, p. 429.

SORsBY (1940):-Modern Trends in Ophthalmology. London.

Thomson, A. M., GRIFfith, H. D.. MUtch, J. R. and LUBBock, D. M. (1939), Brit. Jl. Ophthal., Vol. XXIII, p. 461.

WAGENMÁN , A. (1890).- A rch.f. Ophthal, Vol. XXXVI, p. 4, Abt. 1.

WARING, H. and LANDGREBE, F. W. (194I).-Jl. Exp. Bioi., Vol. XVIII, p. 80.

ZONDEK, H. (1935).-Diseases of the Endocrine Glands. London.

\title{
WAR INJURIES OF THE EYE* \\ Traumatic Proliferative Choroiditis due to Double Penetrating Foreign Body
}

BY

\author{
Major I. C. MiCHAELSON, R.A.M.C. \\ and Dr. J. KRAUS
}

MANY eyes injured by a foreign body with an exit wound in the posterior part of the globe have presented the following fundal appearance after - the vitreous has cleared sufficiently to permit of detailed ophthalmoscopy. A white mass of varying size can be seen in the area of choroido-retinal atrophic change. The whiteness is frequently nilk-like and may be glistening with a few dots of crystalline brightness on its surface. The mass looks solid

* Réceived for publication, July 10, 1943. 
As ophthalmologists it is our obvious duty to press for a proper ophthalmic service for all classes of the community by qualified medical practitioners with ophthalmic training who should receive an adequate fee for their work. A revision and extension of the National Ophthalmic Treatment Board would seem to be the ideal solution of our part of the problem.

We view with alarm the prospect of state control of the voluntary hospitals and we think that free choice of doctor must be accorded to the patient for the success of any scheme of re-organization of the health services. And, lastly, a similar freedom should be meted out to the medical practitioner. May we not agree with that great Scottish physician who, in one of his prefaces, said he thought, with Adam Smith, that a mediciner should be as free to exercise his gifts as an architect or a mole catcher?

\section{A Singular Error}

Madame de Staël's well known epithet vulgaire, applied to the writings of Jane Austen, was a blow which staggered lovers of the Hampshire novelist's books until some one suggested that the adjective in this case meant "commonplace" rather than "low." Thence onwards everything was comfortable. Our own comfort is often disturbed round about the beginning of each month by the fear that we have missed some dreadful howler in reading the proofs: Could a graph of our feelings be constructed it would show a regular rise and fall each month over a good many years with occasional excrescences above the common level where we have blundered more than usual. We regret to have to record that this happened in our October number, where, on page 436, occur the words " There is little or no data." We understand that this slipshod construction is increasingly common in physical literature. That such a monstrous error should be prevalent is indeed a flaw in a centuries-long system of classical education. There is, however, no reason to despair, all will be well when the new Education Act is passed and we may look forward with confidence to the time when, in the words of our erudite Minister of Education, the boy well grounded in Latin will "take" (not only) "the internal combustion engine" (but also the whole range of physics) "in his stride." 